Exper i ment al Mul $\mathrm{i}$ - obj ect i ve Eval uat $\mathrm{i}$ on of Radi al and Loop Di st $\mathrm{r}$ i but i on Net wor $\mathrm{k}$ Conf i gur at i on Usi ng Di st ri but i on Net wor $k$ Equi prent

\begin{tabular}{|c|c|}
\hline 著者 & $\begin{array}{l}\text { SAKAl Shi gekazu, HAYASH Yasuhi ro, KAWASAK } \\
\text { Shoj i, MATSUK Jyunya, FUMA Yoshi aki, MORI } \\
\text { Kenj i ro }\end{array}$ \\
\hline $\begin{array}{l}\text { journal or } \\
\text { publ i cat } i \text { on title }\end{array}$ & $\begin{array}{l}\text { I EEJ TRANSACTI ONS ON ELECTRI CAL AND ELECTRON C } \\
\text { ENG NEERI NG }\end{array}$ \\
\hline vol une & 3 \\
\hline nunber & 5 \\
\hline page $r$ ange & 530539 \\
\hline year & 2008-09 \\
\hline URL & ht t p: //hdl . handl e. net /10098/2047 \\
\hline
\end{tabular}




\title{
Experimental Multi-objective Evaluation of Radial and Loop Distribution Network Configuration Using Distribution Network Equipment
}

\author{
Shigekazu Sakai*, student member, Yasuhiro Hayashi*, member, Shoji Kawasaki*, member, \\ Junya Matsuki*, member, Yoshiaki Fuwa**, member, Kenjiro Mori**, member
}

In this paper, the authors propose an experimental multi-objective evaluation method based on use of distribution network equipment to evaluate distribution network configuration candidates with distributed generators such as photovoltaic generation system and wind power generation system by hourly changing states of sectionalizing switches satisfied with constraints of voltage and line current limit. In the proposed experimental multi-objective evaluation method, the optimal network configuration is determined by using multi-objective evaluation based on total distribution loss rate, maximum voltage total harmonic distortion, and maximum voltage imbalance rate in order to reduce distribution loss and keep power quality. The proposed method is applied to radial and loop distribution network configuration by using an experiment of scaled-down three-phase distribution network with one bank distribution transformer, 5 distribution lines, 5 sectionalizing switches, 12 single-phase loads and 5 DGs.

Keywords : Distribution network, Distributed generator, Sectionalizing switch, Distribution loss, Voltage total harmonic distortion, Voltage imbalance rate, Sending voltage

\section{INTRODUCTION}

Since a distribution system with many feeders has many sectionalizing switches, there are huge radial network configuration candidates by determining states (opened or closed) of sectionalizing switches. Recently, total number of distributed generators (DGs) such as photovoltaic generation system and wind power generation system connected to an actual distribution network increases drastically in Japan. The distribution network connected with many DGs must be operated while keeping reliability of power supply, power quality and loss reduction. Several methodologies to reliably operate distribution systems with DGs have been proposed, and these availabilities have been verified by computer simulation [1]-[17]. However, since computer modeling of the distribution system and DG can not recreate physical phenomenon such as harmonic accurately, the computer simulation can not correctly evaluate the power quality of the distribution network with DGs. Therefore, a novel experimental configuration evaluation method is needed, which is based on power quality data measured in a equipment of distribution network with DGs. So far, an experimental multi-objective evaluation method of the distribution network configuration with DGs has not been proposed from viewpoints of power quality, distribution loss, and reliability of power supply.

In this paper, the authors propose an experimental multi-objective evaluation method based on voltage and current data measured by a distribution network equipment in order to accurately evaluate distribution network configuration candidates with DGs such as photovoltaic generation system and wind power generation system. In the proposed experimental multi-objective

* Graduate School of Electrical and Electronics Engineering, University of Fukui, 3-9-1, Bunkyo, Fukui-City, Fukui, 910-8507, Japan (e-mail: hayashi@fuee.fkui-u.ac.jp).

** Distribution Engineering Group, Distribution Department, Power Network Division, Tokyo Electric Power Company, 1-1-3, Uchisaiwai, Chiyoda, Tokyo, Japan, 100-8560, Japan (e-mail: fuwa.yoshiaki@tepco.co.jp). evaluation method, the optimal network configuration is determined in order to reduce distribution loss and keep power quality by using multi-objective evaluation based on total distribution loss rate, maximum voltage total harmonic distortion, and maximum voltage imbalance rate. The proposed method is applied to an experiment of scaled-down three-phase distribution network with 4 photovoltaic generation systems and a wind power generation system in order to realize the multi-objective evaluation based on measured power quality data while recreating various network configuration candidates. The results obtained by the proposed experimental multi-objective evaluation for radial and loop distribution network configuration with DGs are shown and compared to the conventional evaluation.

\section{OUTLINE OF DISTRIBUTION NETWORK EQUIPMENT}

Distribution network equipment installed in University of Fukui in Japan is a three-phase $200 \mathrm{~V}$ distribution network that $6.6 \mathrm{kV}$ distribution one is scaled down. The photograph and structure of the scaled-down three-phase distribution network equipment are shown in Fig.1 and Fig.2, respectively. This equipment has AVR, sending voltage equipment, 7 distribution lines with switch, 18 single-phase constant impedance loads, 5 inverters modeled as DGs, programmable control equipment and digital measuring instrument. Sectionalizing switches states (opened or closed), sending voltage profile (transformer's tap position), single-phase load profile and output of DGs can be controlled by time-series data. Therefore, it is easy to apply the proposed multi-objective evaluation method based on the optimal radial configuration and sending voltage profile to the distribution network equipment. Outline of each equipment is shown in Table 1. 


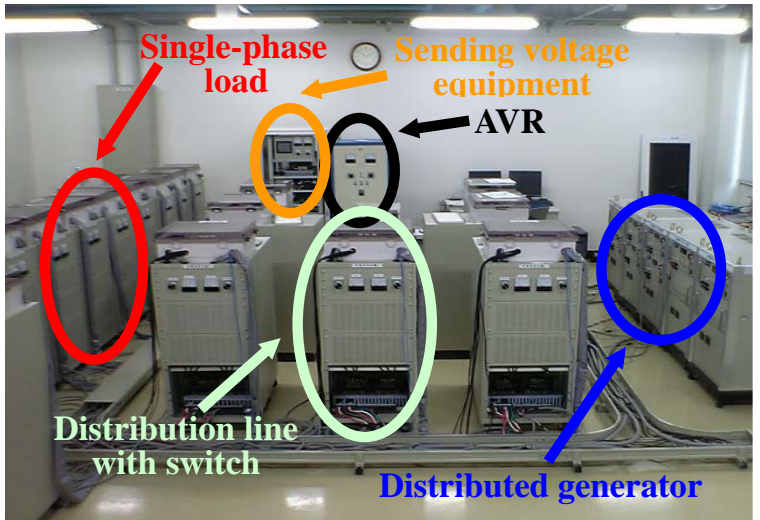

Fig.1. Picture of the scaled-down three-phase distribution network equipment.

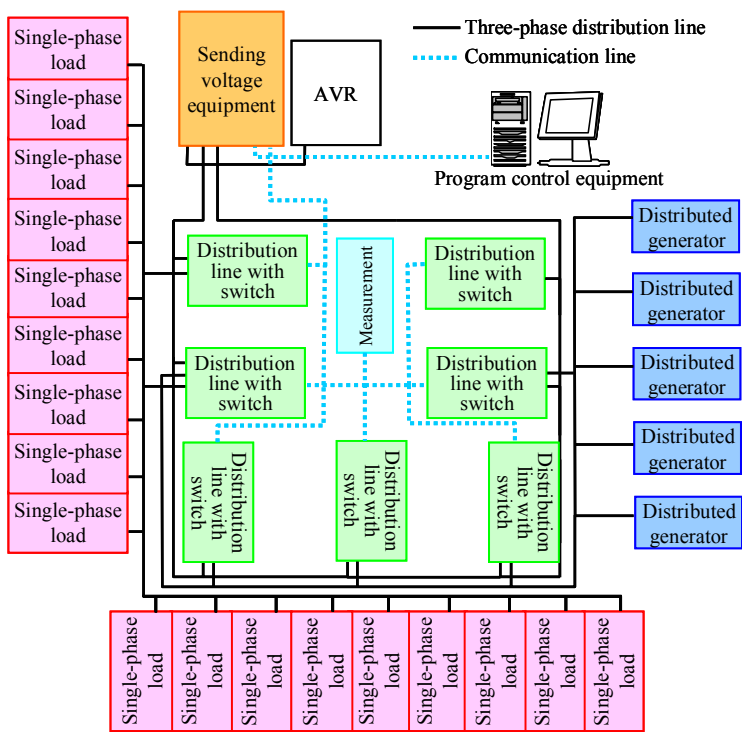

Fig.2. Structure of the scaled-down three-phase distribution network equipment.

\section{EXPERIMENT OF MULTI-OBJECTIVE EVALUATION OF RADIAL AND LOOP DISTRIBUTION CONFIGURATION}

In the proposed multi-objective evaluation method, the optimal network configuration is determined by using multi-objective evaluation based on total distribution loss rate, maximum voltage total harmonic distortion, and maximum voltage imbalance rate in order to reduce distribution loss and keep power quality. Radial network configuration candidate $N$ and loop configuration are evaluated by multi-objective evaluation value $E_{N}$ expressed by Eq.(1)-(4). The network configuration candidate with the minimum multi-evaluation value $\min \left\{E_{N}\right\}$ is determined as the optimal distribution network configuration.

(Total distribution loss rate)

$$
\operatorname{LOSS}_{N}=\left\{\sum_{t=1}^{24} \sum_{j=1}^{5}\left(I_{A t j}^{2}+I_{B t j}^{2}+I_{C t j}^{2}\right) R_{j}\right\} /(\text { Totalload }) \times 100 \ldots
$$

(Maximum voltage THD)

$$
D_{\max N}=\max _{t, i, p}\left\{\frac{\sqrt{V_{5 t i p}^{2}+V_{7 t i p}^{2}}}{V_{1 \text { tip }}} \times 100\right\}
$$

\begin{tabular}{|c|c|}
\hline \multirow{4}{*}{ AVR } & Rar \\
\hline & - Accuracy $180 \mathrm{~V} \sim 220 \mathrm{~V} \pm 3 \mathrm{~V}$ \\
\hline & - Rated capacity: $15 \mathrm{kVA}$. \\
\hline & - Response time: 1s. \\
\hline \multirow{2}{*}{$\begin{array}{l}\text { Sending } \\
\text { voltage } \\
\text { equipment }\end{array}$} & $\begin{array}{l}-2 \mathrm{~V} \text { of } 21 \text { taps from } 180 \mathrm{~V} \text { to } 220 \mathrm{~V} \text { (correspond to } 30 \mathrm{~V} \\
\text { of } 21 \text { taps from } 6300 \mathrm{~V} \text { to } 6900 \mathrm{~V} \text { of } 6.6 \mathrm{kV} \text { distribution } \\
\text { system). }\end{array}$ \\
\hline & $\begin{array}{l}\text { Tap position can be controlled by digital signal from } \\
\text { PC. }\end{array}$ \\
\hline \multirow{4}{*}{$\begin{array}{l}\text { Distribution } \\
\text { line with } \\
\text { switch }\end{array}$} & - Aluminum wire 120mm2 (ALOE120) model. \\
\hline & $\begin{array}{l}\text { nalizing switch can } \\
\text { C. }\end{array}$ \\
\hline & rom $0 \mathrm{~km}$ to $1.5 \mathrm{~km}$. \\
\hline & $\cdot$ Line \\
\hline \multirow{3}{*}{$\begin{array}{l}\text { Single-phase } \\
\text { load } \\
\text { (constant } \\
\text { impedance } \\
\text { load) }\end{array}$} & $\begin{array}{l}\text { Rated current 2A, constant impedance load } \\
\text { (correspond to 50A of } 6.6 \mathrm{kV} \text { distribution system). }\end{array}$ \\
\hline & $\begin{array}{l}\text { - Combination of R, L, and C (R:29, L: } 9 \text { and C: 8) can } \\
\text { be controlled by digital signal from PC. }\end{array}$ \\
\hline & $\begin{array}{l}\text { Heavy load and light load model (downtown, } \\
\text { industrial, residence, and rural area). }\end{array}$ \\
\hline \multirow{6}{*}{$\begin{array}{l}\text { Distributed } \\
\text { generator } \\
\text { (constant } \\
\text { power load) }\end{array}$} & - Pulse width modulation (PWM). \\
\hline & $\begin{array}{l}\text { - Switching frequency (chopper: } 18 \mathrm{kHz} \text {, inverter } \\
9 \mathrm{kHz} \text { ). }\end{array}$ \\
\hline & $\begin{array}{l}\text { Output current harmonic distortion (THD } \leqq 5 \% \text {, } \\
\text { distortion of each harmonic order } \leqq 3 \%) \text {. }\end{array}$ \\
\hline & $\begin{array}{l}\text { - Output of active power, reactive power, and current } \\
\text { can be controlled by digital signal from PC. } \\
\end{array}$ \\
\hline & $\begin{array}{l}\text { Distributed generator modeled by positive signal, } \\
\text { constant power load modeled by negative signal. }\end{array}$ \\
\hline & $\begin{array}{l}\text { Output range of active power: }-9.2 \mathrm{~kW} \sim 9.2 \mathrm{~kW} \text {, Output } \\
\text { range of reactive power: }-9.2 \mathrm{kvar} \sim 9.2 \mathrm{kvar} \text {, and Output } \\
\text { range of line current: } 0 \mathrm{~A} \sim 26 \mathrm{~A} \text {. }\end{array}$ \\
\hline \multirow{5}{*}{$\begin{array}{l}\text { Digital } \\
\text { measuring } \\
\text { instrument }\end{array}$} & - Measurement (measured data are saved as CSV files). \\
\hline & $\begin{array}{l}\text { Line voltage of primary transformer and secondary } \\
\text { transformer (root-mean-square value). }\end{array}$ \\
\hline & $\begin{array}{l}\begin{array}{l}\text { Phase voltage of } \\
\text { (instantaneous value). }\end{array} \\
\end{array}$ \\
\hline & $\begin{array}{l}\text { Line current, Phase voltage of node (instantaneous } \\
\text { value). }\end{array}$ \\
\hline & Sampling time: $10 \mu \mathrm{s} \sim 10 \mathrm{~s}$. \\
\hline \multirow{2}{*}{$\begin{array}{l}\text { Program } \\
\text { control } \\
\text { equipment }\end{array}$} & $\begin{array}{l}\text { inge of input voltage } \pm 5 \mathrm{~V} \text { or } \pm 10 \mathrm{~V} \text { ( } 32 \mathrm{~A} / \mathrm{D} \\
\text { s ). }\end{array}$ \\
\hline & $\begin{array}{l}- \text { OUTPUT: range of output voltage } \pm 5 \mathrm{~V} \text { or } \pm 10 \mathrm{~V} \text { ( } \\
\text { D/A output channels }) .\end{array}$ \\
\hline
\end{tabular}

Table 1. Outline of Distribution Network Equipment

(Maximum voltage imbalance rate)

$$
U_{\max N}=\max _{t, i}\left\{\frac{\left|\dot{V}_{A t i}+\dot{a}^{2} \dot{V}_{B t i}+\dot{a} \dot{V}_{C t i}\right|}{\left|\dot{V}_{A t i}+\dot{a} \dot{V}_{B t i}+\dot{a}^{2} \dot{V}_{C t i}\right|} \times 100\right\}
$$

(Multi-objective evaluation value)

$$
E_{N}=\sqrt{L_{N}^{2}+D_{N}^{2}+U_{N}^{2}}
$$

where $\operatorname{LOSS}_{N}[\mathrm{Wh}]$ is total distribution loss rate of candidate $N(=1 \sim M) ; I_{A t j}, I_{B t j}, I_{C t j}[\mathrm{~A}]$ are each phase line section $j(=1 \sim 5)$ current at $t(=1-24)[\mathrm{h}] ; R_{j}[\Omega]$ is line resistance of line section $j$; $D_{\operatorname{maxN}}[\%]$ is maximum value of voltage THD of candidate $N ; V_{1 t i p}$, $V_{5 \text { tip }}, V_{7 \text { tip }}[\mathrm{V}]$ are $p(=\mathrm{A}, \mathrm{B}, \mathrm{C})$ phase fundamental wave voltage, $5^{\text {th }}$ harmonic voltage, and $7^{\text {th }}$ harmonic voltage at node $i$ at $t[\mathrm{~h}]$, respectively; $U_{\operatorname{maxN}}[\%]$ is maximum value of voltage imbalance rate of candidate $N ; \dot{V}_{A t f i}, \dot{V}_{B t f i}, \dot{V}_{C t f i}$ are A, B, C phase voltage vector at node $i$ at $t[\mathrm{~h}]$, respectively; $\dot{a}$ is vector operator $(\dot{a}=-1 / 2+j \sqrt{3} / 2), E_{N}$ is multi-objective evaluation value of candidate $N ; L_{N}$ is normalized total distribution loss rate of candidate $N ; D_{N}$ is normalized maximum value of THD of candidate $N$; and $U_{N}$ is normalized maximum value of voltage imbalance rate of candidate $N$.

In addition, for the radial configuration candidates and loop configuration, determination of the optimal sending voltage profile is carried out in order to maintain node voltage within the secure 
voltage range. The optimal sending voltage profile is determined so as to minimize total number of tap position's changing per day $E$ and maximize voltage margin $H$ under the voltage and current limit constraints as formulated by Eq.(5)-(13).

[Objective function]

$$
\begin{aligned}
& F=E+\alpha H \rightarrow \text { Minimize ............................. (5) } \\
& E=\sum_{i=1}^{M} \sum_{t=1}^{24} x_{i, t-1}\left(I_{L O A D}, I_{D G}\right)\left\{x_{i, t-1}\left(I_{L O A D}, I_{D G}\right)-x_{i t}\left(I_{L O A D}, I_{D G}\right)\right\}
\end{aligned}
$$

$$
\begin{aligned}
& H=\sum_{i=1}^{M} \sum_{t=1}^{24}\left(V_{\text {TARGET } t}-V_{i t} x_{i t}\left(I_{L O A D}, I_{D G}\right)\right)^{2} \\
& V_{\text {TARGETt }}=\left(V \max _{t}+V \min _{t}\right) / 2
\end{aligned}
$$

[Operational constraints]

(Tap position)

$$
\sum_{i=1}^{M} x_{i t}\left(I_{L O A D}, I_{D G}\right)=1 \quad(t=1,2, \ldots, 24)
$$

(Sending voltage limit)

$$
\begin{aligned}
& V \min _{t} \leq V_{i t} x_{i t}\left(I_{L O A D}, I_{D G}\right) \leq V \max _{t} \\
& (i=1,2, \ldots, M, t=1,2, \ldots, 24) \\
& V \min _{t}=\max \left\{V_{\text {Amint }}, V_{B \min t}, V_{C \text { mint }}\right\} \quad(t=1,2, \ldots, 24) \text {. } \\
& V \max _{t}=\min \left\{V_{\text {Amaxt }}, V_{B \operatorname{maxt}}, V_{C \max t}\right\} \quad(t=1,2, \ldots, 24) .
\end{aligned}
$$

(Each node voltage limit)

$$
\begin{aligned}
\underline{v_{s}} & \leq v_{s w}\left(V_{i t} x_{i t}\left(I_{L O A D}, I_{D G}\right)\right) \leq \overline{v_{s}} \\
& \left(s \in S, w \in W_{s}, i=1,2, \ldots, M, t=1,2, \ldots, 24\right) .
\end{aligned}
$$

where, $I_{L O A D}[\mathrm{~A}], I_{D G}[\mathrm{~A}]$ are profile of load current and DG output current; $x_{i t}\left(I_{L O A D}, I_{D G}\right)$ is $0-1$ variable to determine tap position $i$ at $t(=1-24)[\mathrm{h}]$ (if use 1 , otherwise 0$)\left(x_{i, 0}\left(I_{L O A D}\right.\right.$ $\left.\left.I_{D G}\right)=X_{i, 24}\left(I_{L O A D}, I_{D G}\right)\right) ; E$ is total number of tap position changes per day, $H$ is total error for target voltage; $V_{i t}[\mathrm{~V}]$ is sending voltage at $t[\mathrm{~h}]$ using tap position $I ; \operatorname{Vmin}_{t}[\mathrm{~V}], \operatorname{Vmax}_{t}[\mathrm{~V}]$ are lower and upper voltage limit at $t[\mathrm{~h}] ; V_{\text {TARGETt }}[\mathrm{V}]$ is target sending voltage at $t[\mathrm{~h}] ; S$ is set of pole transformer tap section number; $W_{s}$ is set of feeder section number in pole transformer tap section $s ; v_{s w}\left(V_{i t} x_{i t}\left(I_{L O A D}\right.\right.$, $\left.I_{D G}\right)$ ) is $6.6 \mathrm{kV}$ system voltage based on $V_{i t} x_{i t}\left(I_{L O A D}, I_{D G}\right)$ for feeder section $w$ in pole transformer tap section $s$ at $t[\mathrm{~h}] ; V_{s}, \overline{V_{s}}$ are lower and upper limit of $6.6 \mathrm{kV}$ system voltage in pole transformer tap section $s ; M$ is total number of tap positions(=11); $\alpha$ is coefficient $\left(=10^{-8}\right)$

The proposed method is applied to distribution network equipment. The experimental configuration has one bank distribution transformer, 5 distribution lines, 5 sectionalizing switches, 12 single-phase R-L-C constant impedance loads, one wind power generation system (WP) and 4 photovoltaic generation systems (PVs) as shown Fig.3. Daily active power and reactive power of single-phase load, WP output and PVs output are shown in Fig.4 and Fig.5, respectively. Power factor of PV and WP is set as 1 from viewpoint of the severest condition of voltage rise. Since the experiment configuration has five sectionalizing switches, there are 5 radial distribution network configuration candidates (candidate1-5) and one loop configuration closed all switches. 5 radial distribution network configuration candidates and loop configuration of the distribution network equipment are shown in Fig.6.

After three-phase node voltage and three-phase line current are measured for 5 configuration candidates and loop configuration of distribution network equipment, total distribution loss rate, maximum voltage THD, maximum voltage imbalance rate and multi-objective evaluation value $E_{\mathrm{N}}$ are calculated.

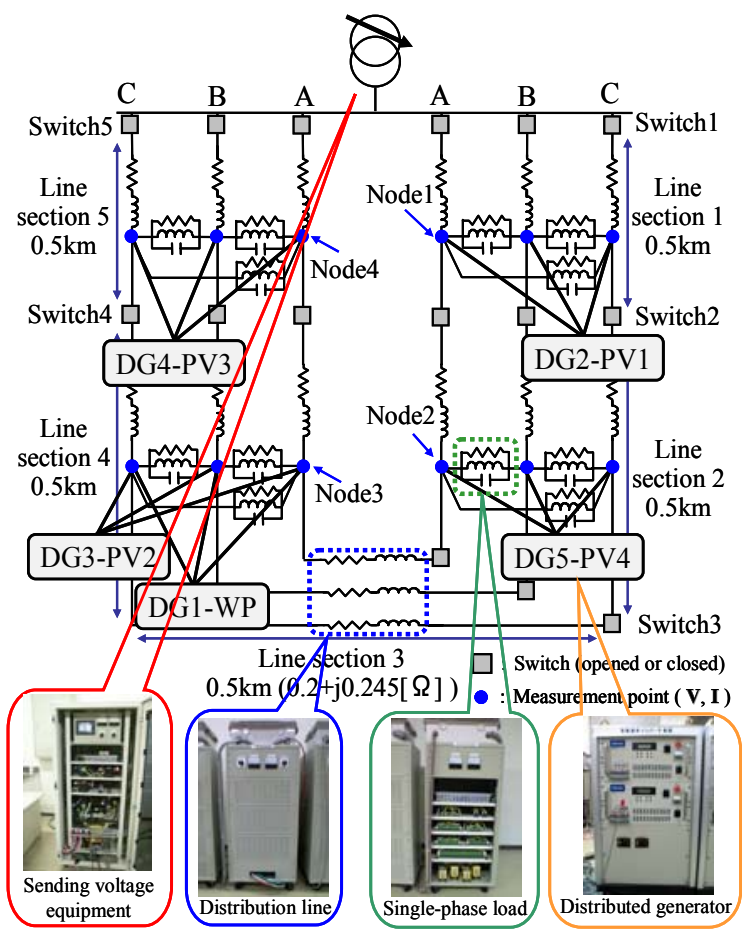

Fig.3. Experiment configuration.

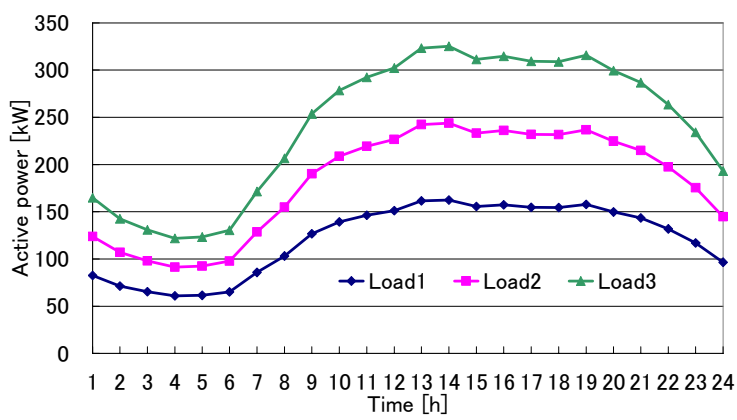

(a) Active power

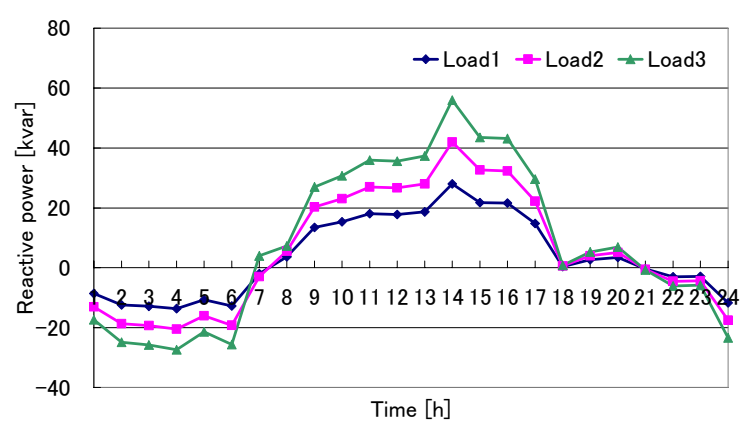

(b) Reactive power

Fig.4. Active power and reactive power of single-phase load. 


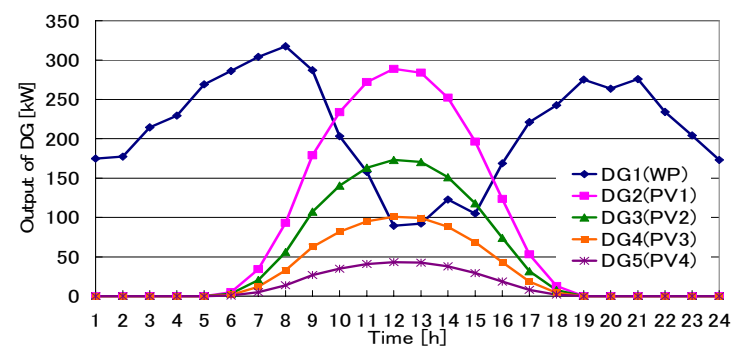

Fig.5. Output of DGs.

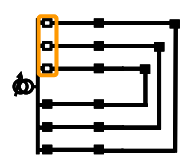

(a) candidate 1

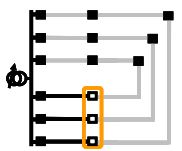

(d) candidate 4

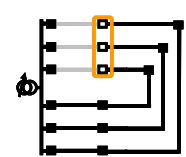

(b) candidate 2

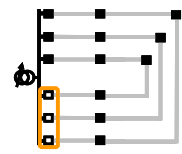

(e) candidate 5

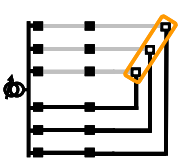

(c) candidate 3

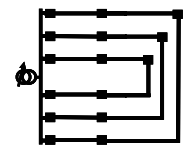

(f) loop
- : Switch (closed) 口: Switch (opened)

Fig.6. Radial distribution network configuration candidates and loop configuration.

\section{EXPERIMENTAL RESULTS OF MULTI-OBJECTIVE EVALUATION OF RADAIAL AND LOOP DISTRIBUTION CONFIGURATION}

Experimental results of total distribution loss rate, maximum voltage THD, maximum voltage imbalance rate, multi-objective evaluation value and optimal sending voltage profile for each configuration and loop configuration are shown in Fig.7-12, respectively. As shown in Fig.7, total distribution loss rate which is a conventional evaluation index decreases after DGs are connected. Fig. 8 and 9 shows that though maximum voltage THD and maximum voltage imbalance rate increase after connecting DGs, maximum voltage THD and maximum voltage imbalance rate are kept within the acceptable range (voltage THD $\leq 5 \%$ and voltage imbalance rate $\leq 3 \%$ ). The optimal configuration obtained by using total distribution loss rate as the conventional index becomes the loop configuration when DG is connected or not. On the other hand, it is seen from Fig.10 that when the multi-objective evaluation value $E_{N}$ as the proposed configuration evaluation index is used, the loop configuration becomes the optimal configuration without DG and configuration candidate 3 becomes the optimal configuration with DGs. Since the power qualities such as voltage THD and imbalance are evaluated by the proposed multi-objective evaluation, the optimal configuration with the minimum multi-objective evaluation value is changed before and after connecting DGs as shown in Fig.10. From Fig.11-12, it is seen that the sending voltage for each configuration and loop configuration can be controlled within the proper range by changing a few tap position.

In addition, in order to evaluate influence of DGs connection to distribution network, before and after connecting DGs, hourly distribution loss rate, hourly maximum voltage THD, and hourly maximum voltage imbalance rate for candidate 3 and loop configuration are shown in Fig.13-15. Furthermore, hourly node voltage THD and hourly node voltage imbalance rate for candidate 3 and loop configuration before and after connecting DGs are shown in Fig.16-19.

From Fig.14, Fig.16 and Fig.17, it can be seen that hourly voltage THD at each node increases before and after connecting DGs, and those increasing rate THD are different by affection of DGs connection. The more it approaches the edge of feeder, the bigger the increasing rate is. As shown in Fig.15, Fig.18 and Fig.19, before and after connecting DGs, though hourly maximum voltage imbalance rate increases, tendency to increase and decrease of hourly node voltage imbalance rate is different in each node, since the hourly node voltage imbalance is depended on hourly load current imbalance.

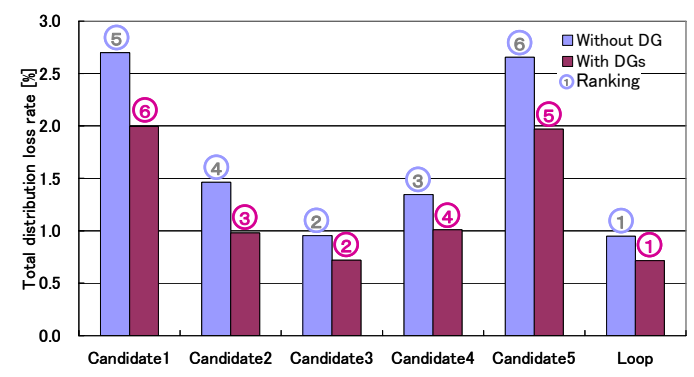

Fig.7. Total distribution loss rate for each candidate and loop configuration.

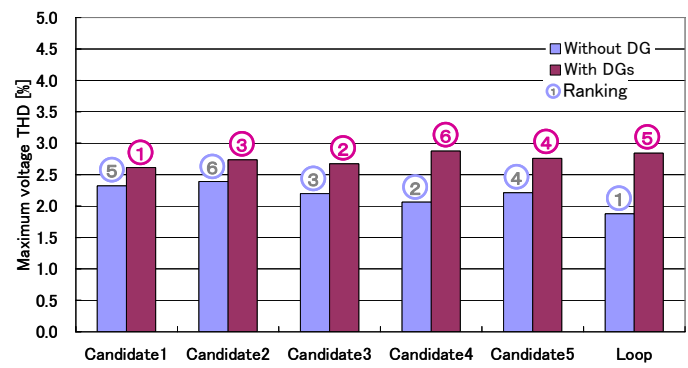

Fig.8. Maximum voltage THD

for each candidate and loop configuration.

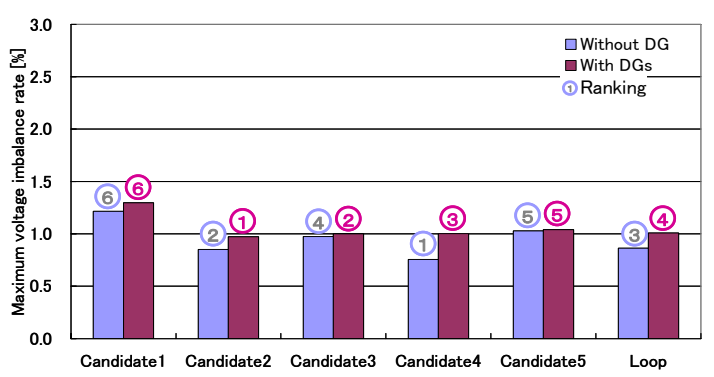

Fig.9. Maximum voltage imbalance rate for each candidate and loop configuration.

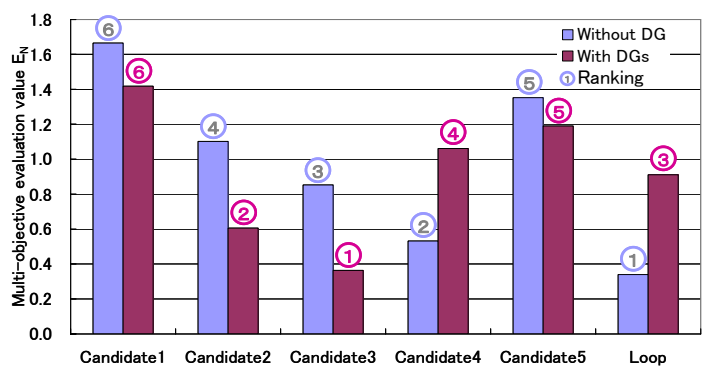

Fig.10. Multi-objective evaluation value for each candidate and loop configuration. 


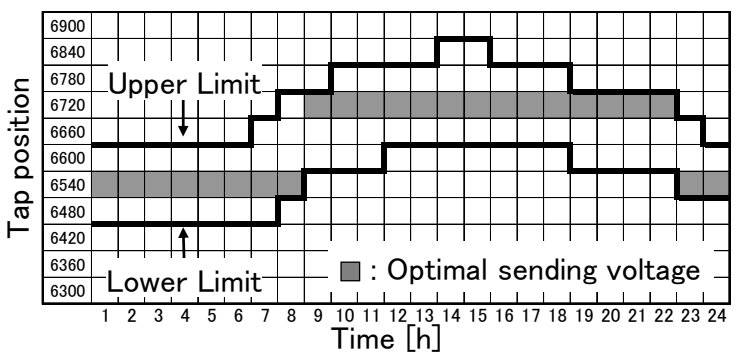

(a) Configuration candidate 1

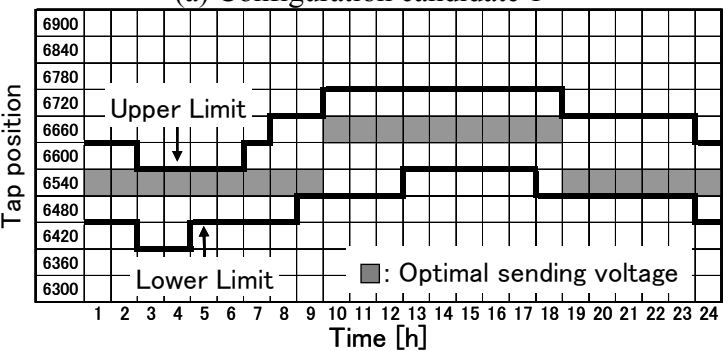

(b) Configuration candidate 2

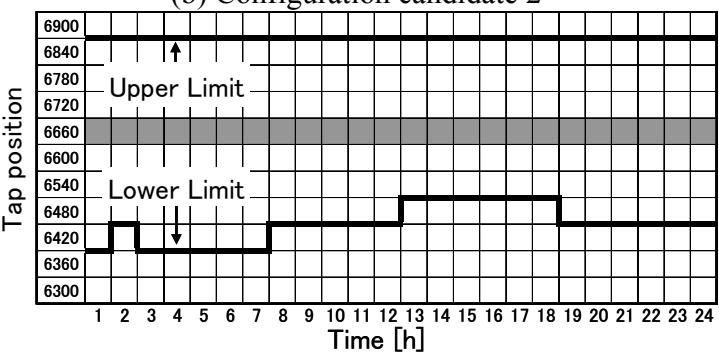

(c) Configuration candidate 3

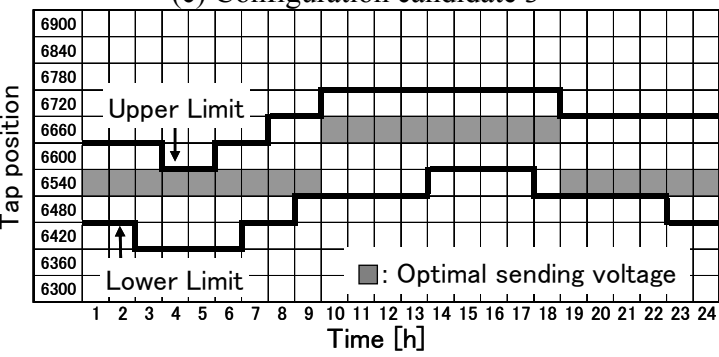

(d) Configuration candidate 4

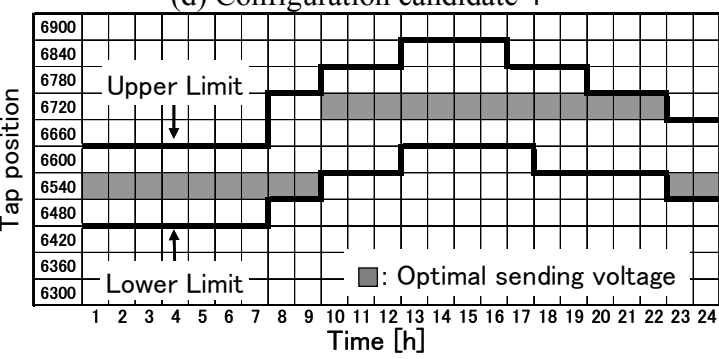

(e) Configuration candidate 5

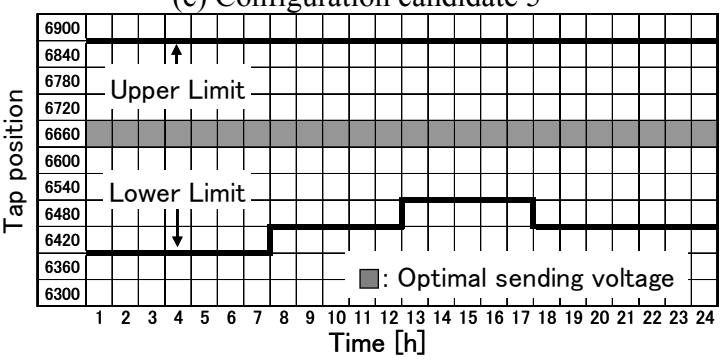

(f) Loop configuration

Fig.11. Optimal sending voltage profile for each candidate and loop configuration without DG.

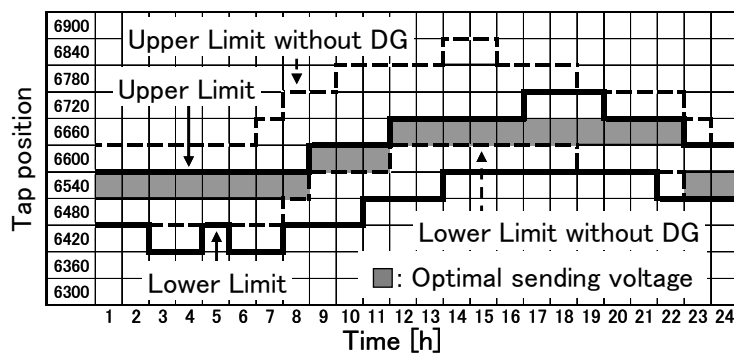

(a) Configuration candidate 1

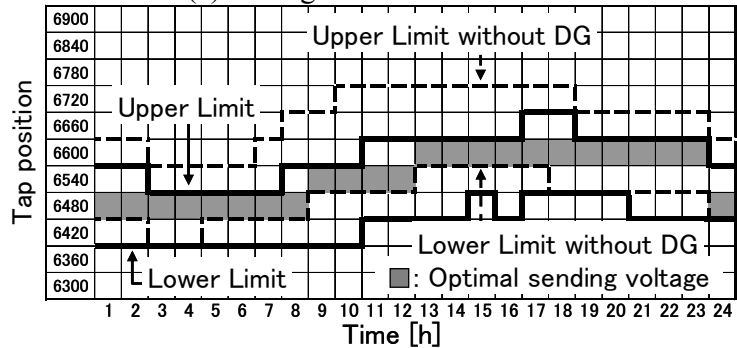

(b) Configuration candidate 2

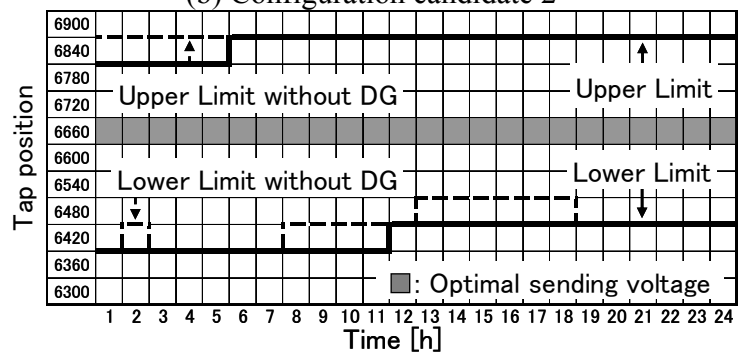

(c) Configuration candidate 3

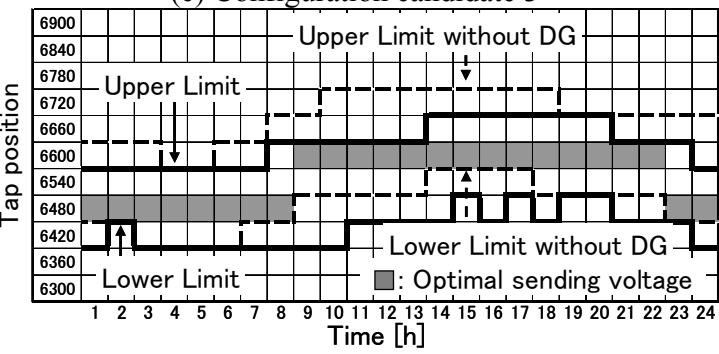

(d) Configuration candidate 4

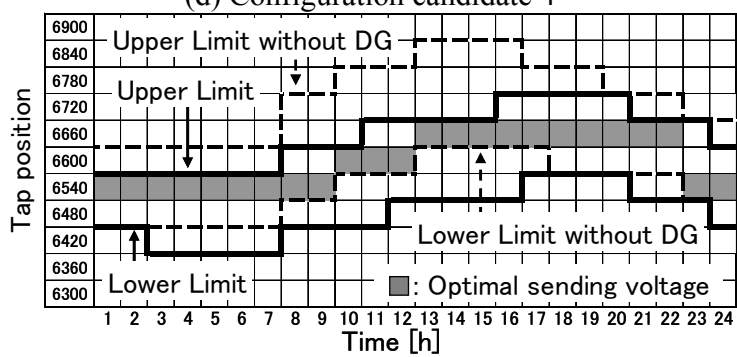

(e) Configuration candidate 5

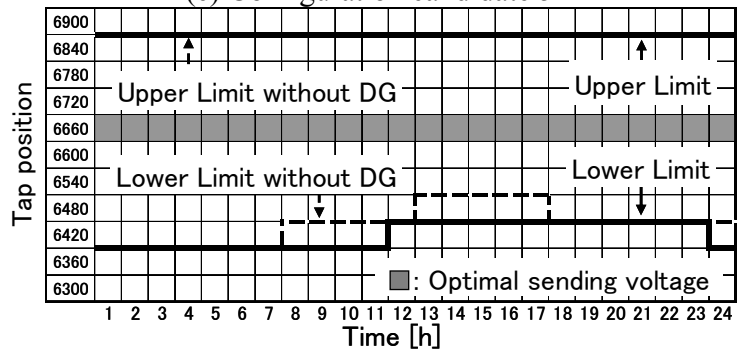

(f) Loop configuration

Fig.12. Optimal sending voltage profile for each candidate and loop configuration with DGs. 


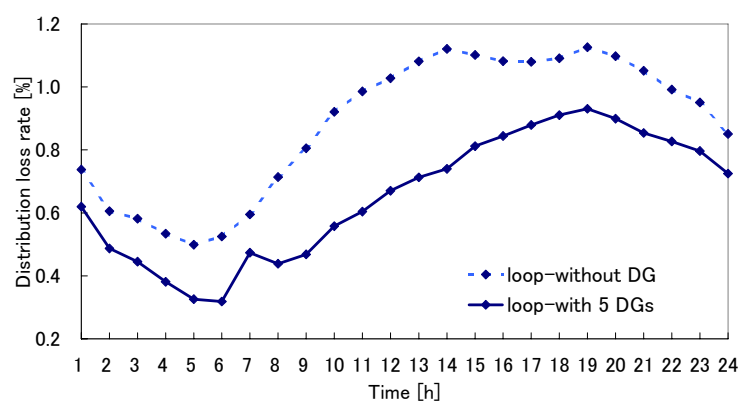

(a) Loop configuration

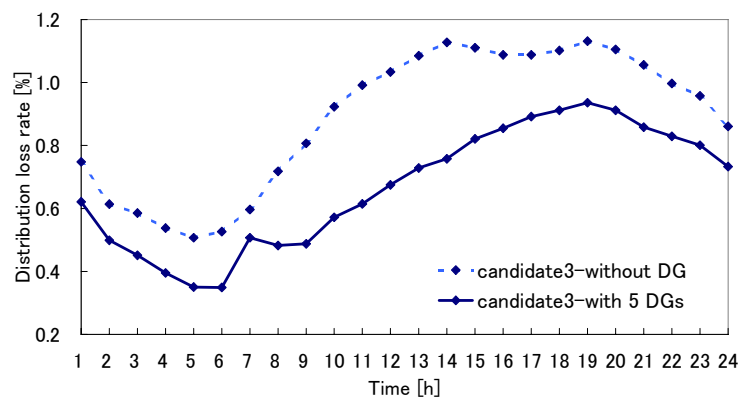

(b) Radial configuration candidate 3

Fig.13. Hourly distribution loss rate before and after connecting DGs.

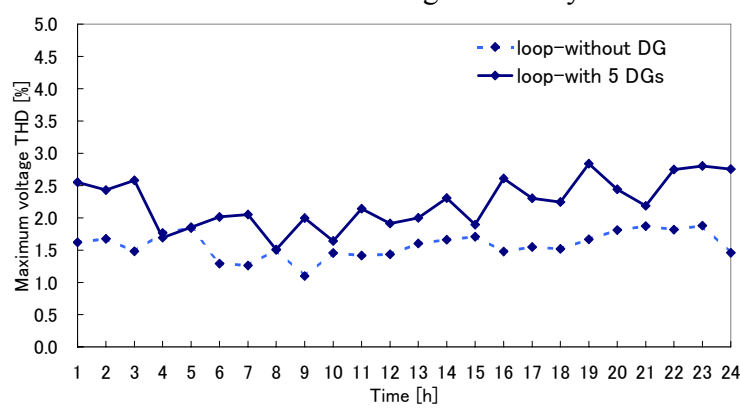

(a) Loop configuration

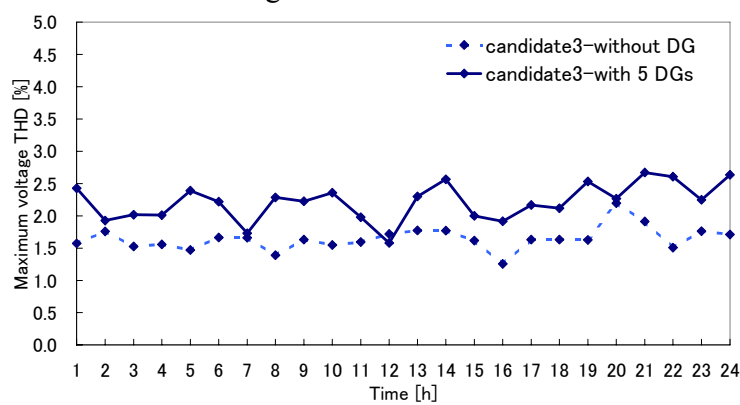

(b) Radial configuration candidate 3

Fig.14. Hourly maximum voltage THD before and after connecting DGs.

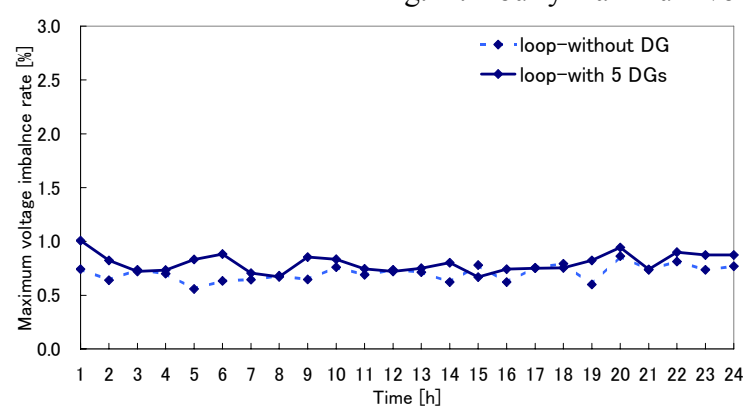

(a) Loop configuration

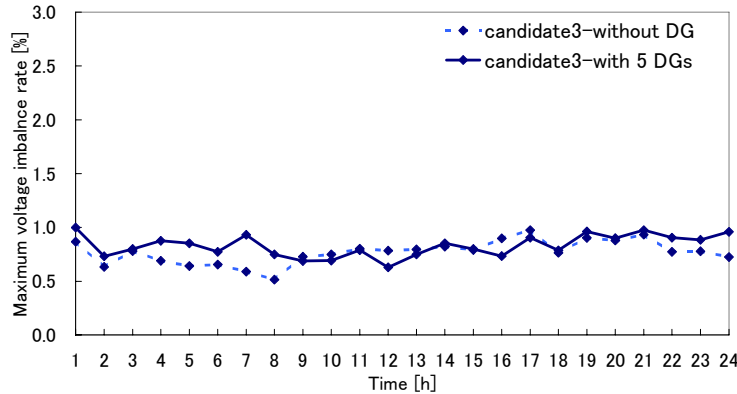

(b) Radial configuration candidate 3

Fig.15. Hourly Maximum voltage imbalance rate before and after connecting DGs.

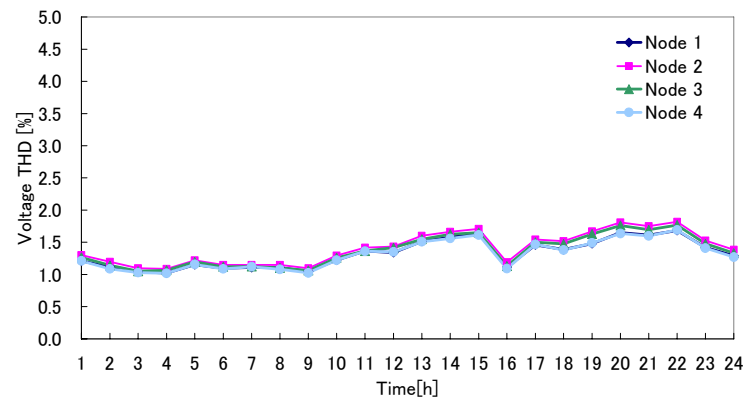

(a) Without DG

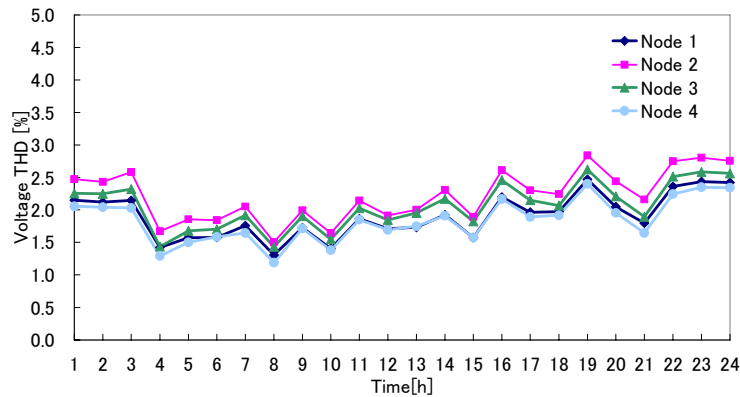

(b) With DGs

Fig.16. Hourly node voltage THD in phase B before and after connecting DGs for loop configuration.

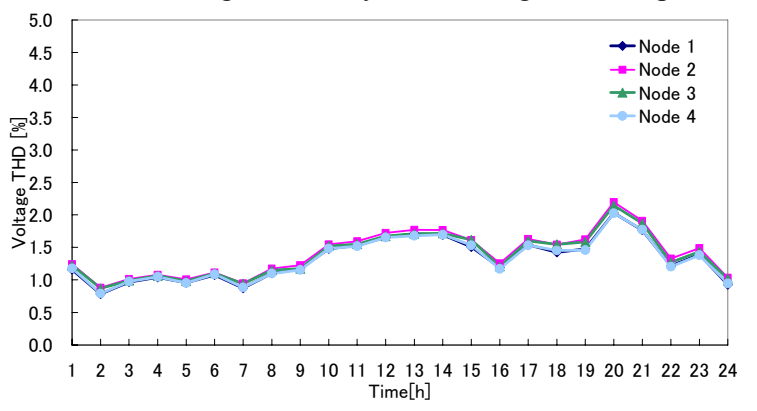

(a) Without DG

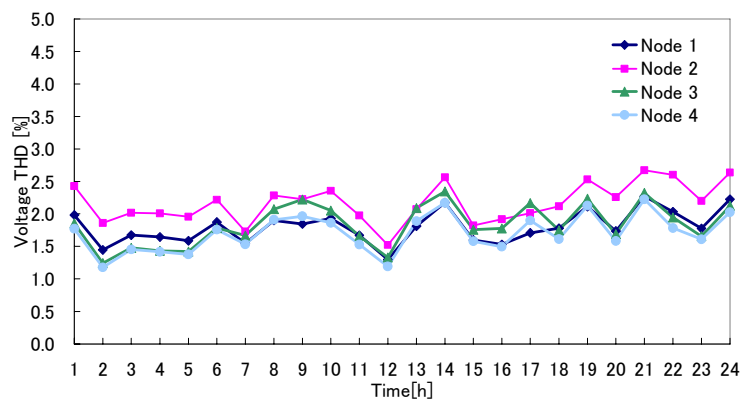

(b) With DGs

Fig.17. Hourly node voltage THD in phase B before and after connecting DGs for radial configuration candidate 3. 


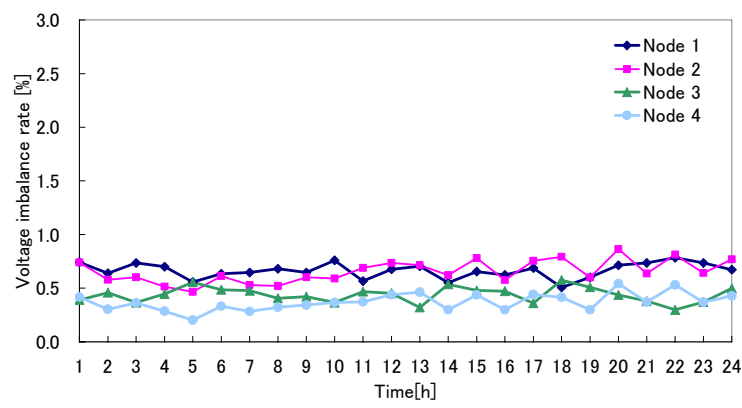

(a) Without DG

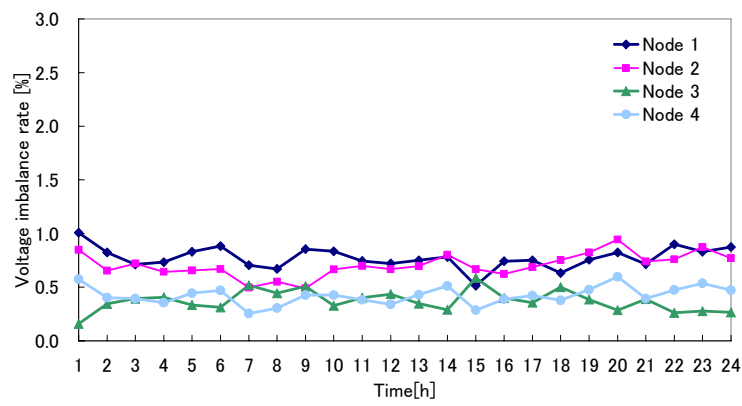

(b) With DGs

Fig.18. Hourly node voltage imbalance rate in phase B before and after connecting DGs for loop configuration.

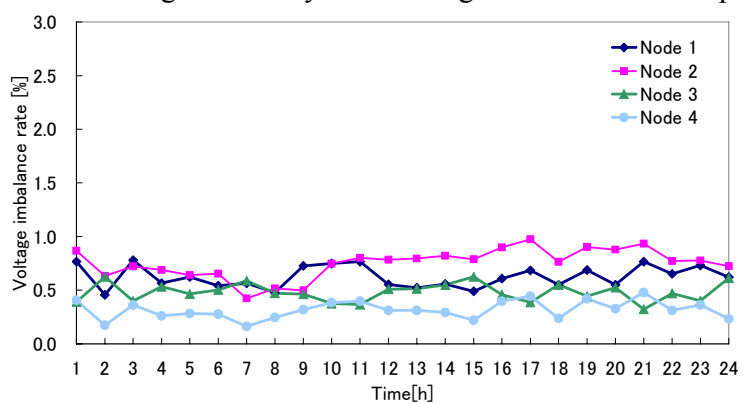

(a) Without DG

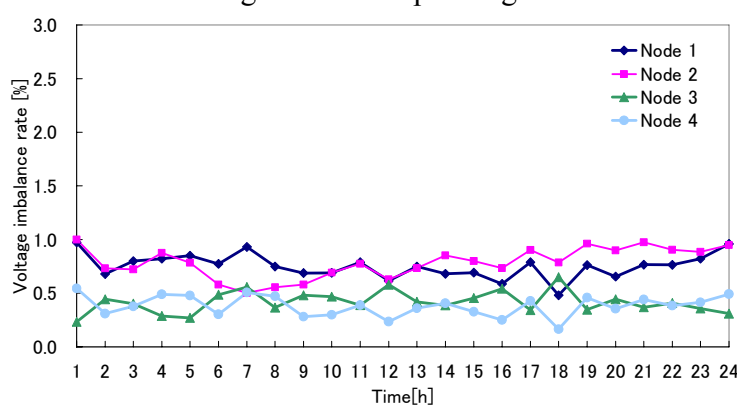

(b) With DGs

Fig.19. Hourly node voltage imbalance rate in phase B before and after connecting DGs for radial configuration candidate 3 .

\section{CONCLUSION}

In this paper, an experimental multi-objective evaluation method of distribution network configuration candidates with distributed generators by using distribution network equipment was proposed. The optimal network configuration candidate can be determined by using multi-objective evaluation based on total distribution loss rate, maximum voltage total harmonic distortion and maximum voltage imbalance rate in order to reduce distribution loss and keep power quality. The proposed method is applied to an experiment of scaled-down three-phase distribution network with 4 photovoltaic generation systems and a wind power generation system. As the experimental results, it was shown that the total distribution loss rate of configuration decreases and the maximum voltage THD increases of configuration before and after connecting DGs. Since the power qualities such as voltage THD and imbalance are evaluated in the proposed multi-objective evaluation method, it was seen that the optimal configuration obtained by the proposed multi-objective evaluation is changed before and after connecting DGs.

This study was supported by Industrial Technology Research Grant Program in '04 from New Energy and Industrial Technology Development Organization (NEDO) of Japan.

(Manuscript received December. 3, 2007,

revised May 29, 2008)

\section{References}

(1) G. W. Ault, C. E. T. Foote, and J. R. McDonald, "Distribution system planning in focus", IEEE Power Engineering Review, January 2002, pp.60-63

(2) R. C. Dugan, and T. E. Mcdermott, "Distributed generation", Industry Applications Magazine, IEEE, Vol. 8, Mar/Apr 2002, pp.19-25

(3) Y. G. Hegazy, M. M. A. Salama, and A. Y. Chikhani, "Adequacy assessment of distributed generation systems using Monte Carlo Simulation", IEEE Trans, Power Systems, Vol. 18, No. 1, February 2003, pp.48-52

(4) S. Naka, T. Genji, T. Yura, and Y. Fukuyama, "A hybrid particle swarm optimization for distribution state estimation", IEEE Trans, Power Systems, Vol. 18, No. 1, February 2003, pp.60-68

(5) A. A. Chowdhury, S. K. Agarwal, and D. O. Koval, "Reliability modeling of distributed generation in conventional distribution systems planning and analysis", IEEE Trans, Industry Applications, Vol. 39, No. 5, September/October 2003, pp.1493-1498

(6) Y. Mao, and K. N. Miu, "Switch placement to improve system reliability for radial distribution systems with distributed generation", IEEE Trans, Power Systems, Vol. 18, No. 4, November 2003, pp.1346-1352

(7) Y. Hayashi, J.Matsuki, "Loss Minimum Configuration of Distribution System Considering N-1 Security of Dispersed Generators", IEEE Trans. Power Systems, vol. 19, No. 1, 2004, pp. 636-642

(8) W. El-Khattam, Y. G. Hegazy, and M. M. A. Salama, "An integrated distributed generation optimization model for distribution system planning", IEEE Trans, Power Systems, Vol. 20, No. 2, May 2005, pp.1158-1165

(9) W. El-Khattam, Y. G. Hegazy, and M. M. A. Salama, "Investigating distributed generation systems performance using Monte Carlo simulation", IEEE Trans, Power Systems, Vol. 21, No. 2, May 2006, pp.524-532

(10) E. Carpaneto, G. Chicco, and J. S. Akilimali, "Branch current decomposition method for loss allocation in radial distribution systems with distributed generation", IEEE Trans, Power Systems, Vol. 21, No. 3, August 2006, pp.1170-1179

(11) In-Su Bae, and Jin-O Kim, "Reliability evaluation of distributed generation based on operation mode", IEEE Trans, Power Systems, Vol. 22, No. 2, May 2007, pp.785-790

(12) S. Khushalani, J. M. Solanki, and N. N. Schulz, "Development of three-phase unbalanced power flow using PV and PQ models for distributed generation and study of the impact of DG models", IEEE Trans, Power Systems, Vol. 22, No. 3, August 2007, pp.1019-1025

(13) In-Su Bae, Jin-O Kim, Jae-Chul Kim, and C. Singh, "Optimal operating strategy for distributed generation considering hourly reliability worth", IEEE Trans, Power Systems, Vol. 19, No. 1, February 2004, pp.287-292

(14) M. Nagpal, F. Plumptre, R. Fulton, and T. G. Martinich, "Dispersed generation interconnection-utility perspective", IEEE Trans, Industry Applications, Vol. 42, No. 3, May/June 2006, pp.864-872

(15) M. Thomson, and D. G. Infield, "Network power-flow analysis for a high penetration of distributed generation", IEEE Trans, Power Systems, Vol. 22, No. 3, August 2007, pp.1157-1162

(16) Y. Zhu, and K. Tomsovic, "Adaptive power flow method for distribution systems with dispersed generation", IEEE Trans, Power Delivery, Vol. 17, No. 3, July 2002, pp.822-827

(17) A. Losi, and M. Russo, "Dispersed generation modeling for object-oriented distribution load flow", IEEE Trans, Power Delivery, Vol. 20, No. 2, July 2005, pp. $1532-1540$ 


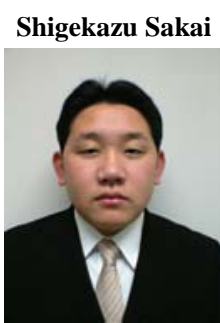

(Member) was born in Fukui, Japan, on May 7, 1982. He received the B.S. and M.S. degrees in electrical engineering from University of Fukui, Fukui, Japan in 2005 and 2007, respectively. Since 2007, he has been with University of Fukui and teaching in the faculty. His area of research is cooperative operation and control of distribution system connecting distributed generators.

Yasuhiro Hayashi

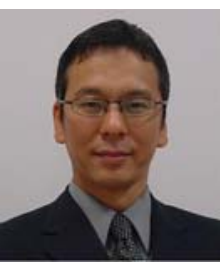

(Senior Member) was born in Fukui, Japan, on January 5, 1967. He received the B.E., M.E., and Doctor of Engineering degrees from Waseda University, Tokyo, Japan, in 1989, 1991, and 1994, respectively. Currently, he is an Associate Professor in the Department of Electrical and Electronics Engineering at University of Fukui, Fukui, Japan. In 1994, he became a Research Associate at Ibaraki University, Hitachi, Japan. His research fields of interest include optimization of power system operation and planning, power system analysis, and load forecasting.

Shoij Kawasaki

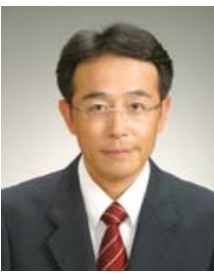

(Member) was born in Fukui, Japan, on July 1, 1968. He received the B.S. and M.S. degrees in electrical engineering from Fukui University, Fukui, Japan in 1991 and 1993, respectively. He joined Komatsu Ltd. in April 1993. And he joined the Department of Electrical and Electronics Engineering, Fukui University in May 1994, where he is currently an Assistant Professor. His research interests are optimization of distribution network configuration, and power quality of distribution network.

Junya Matsuki

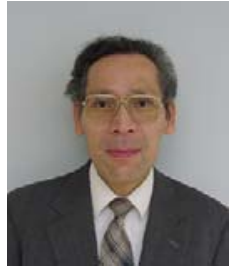

(Senior Member) was born in Kumamoto, Japan, on December 21, 1946. He received the B.S., M.S., and Doctor of Engineering degrees in electrical engineering from Kyoto University, Kyoto, Japan, in 1969, 1971, and 1979, respectively. Currently, he is a Professor at University of Fukui, Fukui, Japan. He joined the Mitsubishi Electric Company, Tokyo, Japan, in 1971. Since then, he has been interested in power system analysis and synchronous machines.

Yoshiaki Fuwa

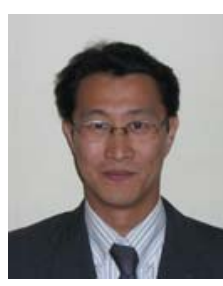

(Member) was born in Hokkaido, Japan, on June 26, 1971. He received the B.S. and M.S. degrees in electrical engineering from Osaka University, Osaka, Japan in 1994 and 1996, respectively. He joined Tokyo Electric Power Company in April 1996. And he joined the Distribution Department. Currently, he engages in a study about the distribution system network.

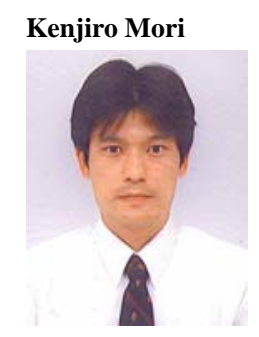

(Member) was born in Gifu, Japan, on February 23, 1974. He received the B.S. and M.S. degrees in electrical engineering from Nagoya University, Nagoya, Japan in 1996 and 1998, respectively. $\mathrm{He}$ joined Tokyo Electric Power Company in April 1998. And he joined the Distribution Department. Currently, he engages in a study about the distribution system network. 